\title{
EL CONCEBIDO IN VITRO CRIOCONSERVADO COMO SUJETO DE DERECHO Y SU TRATAMIENTO DENTRO DE UN PROCESO DE DIVORCIO*
}

\author{
Luisa Villena Barahona**
}

Recibido: 25.08 .2015

Aprobado: 04.10.2015

\section{RESUMEN}

El estudio trata sobre la problemática en torno al tratamiento del concebido in vitro crioconservado, cuando una pareja por motivos diversos no llega a consumar la inserción de los embriones creados in vitro en el cuerpo de la mujer, ya sea porque cambiaron de opinión -decidieron separarse-, se divorcian o uno de los cónyuges o ambos fallecen.

\section{ABSTRACT}

The study deals with the problems surrounding the fate of cryopreserved embryos obtained in in vitro fertilization cycles, when a couple fails, for a number of reasons, to insert embryos created in the laboratory into the wife's womb, either because they changed their minds -decided to separate- divorced or one of the spouses, or both, dies.

PALABRAS CLAVE

Crioconservación - Embriones congelados - Criogenia

\section{KEY WORDS}

Cryopreservation - Frozen embryos - Cryogenics

\section{INTRODUCCIÓN}

Existe una problemática latente que hasta la fecha no tiene atención, cual es la falta de regulación jurídica del destino de los embriones crioconservados, quienes luego de haber sido creados in vitro, no son implantados por diversos motivos.

Nuestro país carece de una legislación específica sobre esta materia, dejando un preocupante vacío, más preocupante todavía por involucrar un tema tan importante como la vida. El presente trabajo no pretende plantear conclusiones definitivas, sino contribuir con el debate, creando mayor conciencia del tema, y así aportar posibles soluciones; todo ello en busca de la mejor protección de la vida humana, desde la concepción.

\section{Planteamiento del problema}

El avance de la ciencia ha facilitado la reproducción humana con técnicas de reproducción asistida. Estos cambios han traído consigo una serie de situaciones que tienen efectos legales que nuestra legislación aún no contempla, suscitándose diversos problemas en la cotidianidad de las personas que recurren a estas nuevas formas

* Resumen de la tesis sustentada por la autora, bajo el mismo título, para optar el título de Abogada en la Facultad de Derecho de la Universidad Femenina del Sagrado Corazón, en el año 2014.

** Egresada de la Facultad de Derecho de la UNIFE y ex representante estudiantil ante el Consejo de Facultad. Alumna de la Maestría en Bioética y Biojurídica de la Universidad Santo Toribio de Mogrovejo. 
de procreación, creándose una afectación en las relaciones sociales y jurídicas.

Estos inconvenientes tienen que ver con el desmedido desarrollo social y científico frente a las normas del Derecho, lo que requiere entonces que se establezca un límite o un parámetro legal que contemple y ampare el derecho a la vida desde su procreación, sea natural 0 asistida.

El problema surge cuando una pareja que se somete al tratamiento in vitro, no llega a consumarlo por algún motivo, sea porque: cambian de opinión, deciden separarse, se divorcian o uno de los cónyuges o ambos fallecen; se genera entonces un problema, ya que existe un óvulo fecundado esperando ser implantado y ese concebido, ahora embrión, se mantiene en crioconservación esperando que alguien lo reclame y así poder desarrollarse autónomamente.

Ante esta situación nos preguntamos: ¿Qué sucede con ese concebido in vitro?, ¿debería ser desechado?, ¿es sujeto de derechos?, ¿qué derechos tienen los padres sobre él?

Se trata de un problema real que ya se da en otros países y que en un futuro cercano podría darse en nuestro entorno. Siendo así, es importante determinar si este concebido es sujeto de derechos y si existe una suerte de derechos de tenencia o disposición de este nuevo ser por parte de sus padres

Debido a que en el Perú no hay estadísticas oficiales sobre esta problemática, no tenemos un referente que pueda darnos una cifra de los casos que se hayan podido presentar. En el plano legal, la Constitución protege la vida desde su concepción, pero falta regular el tratamiento de los llamados "bebés probeta".

\section{AnteCedentes teóRICos}

El Derecho le da la calidad de persona al hombre, solo el hombre es persona y toda persona es hombre (en el sentido de "ser humano"). Ahora bien, a toda persona le pertenecen derechos adquiridos por el simple hecho de existir y le son inherentes un conjunto de atributos jurídicos que necesariamente le corresponden, ${ }^{1}$ lo cual se hace extensivo al concebido.

La vida empieza desde el momento de la fecundación, siendo ésta un proceso y no un suceso único, por el cual ocurre la fusión de los gametos masculino y femenino, produciéndose así el embrión. Puede, además, empezar la vida con la sustitución de un núcleo de un ovocito por una célula somática, originando así un embrión somático.

El bien jurídico que protege el Derecho, representa intereses relevantes de las personas en tanto, sujetos sociales. La vida en sociedad requiere de la protección de ciertas normas e intereses individuales y de ciertos límites de relación entre los sujetos, y de relación entre el poder estatal y los sujetos, en tanto, la colectividad y no un grupo específico sean los beneficiarios. Desde este punto de vista, el bien jurídico no es patrimonio solo del derecho represivo sino del derecho como regulador de relaciones interpersonales y sociales.

Existe cierta discusión en doctrina con respecto al bien jurídico protegido alrededor del concebido, pero las diferencias en realidad son más de forma que de contenido.

El bien jurídico tutelado o protegido es el derecho a la vida del fruto de la concepción. En este sentido, la jurisprudencia encontrada es unánime respecto a que lo que se protege es la vida del feto, de tal modo que se ha dicho que "la no comprobación de que haya existido un feto con vida y que la conservara al momento del hecho impide tener por configurados los requisitos de la figura en cuestión".

El derecho a la vida presenta la siguiente naturaleza: ${ }^{2}$

- Es una cualidad consustancial al ser humano.

- Está reconocido en nuestro sistema legislativo.

- Se encuentra protegido en nuestro sistema legislativo.

León Barandarian, José (2001). Curso Elemental de Derecho Civil Peruano. Segunda Edición. Lima, Imprenta de la Universidad Nacional Mayor de San Marcos, p. 95.

2 Fernández Sessarego, Carlos (1997). Nuevas Tendencias en el Derecho de las Personas. Lima, Universidad de Lima, p. 68. 
- Es un derecho intransferible e irrenunciable por ser el principal derecho y el fundamental que es inherente al ser humano.

\section{Algunas referencias al DERECHO A LA VIDA EN NUESTRA LEGISLACIÓN}

El Código Civil de 1984, en su artículo primero dice: "La persona humana es sujeto de derecho desde su nacimiento." En consecuencia, en nuestra legislación, la persona humana existe como tal a partir solo de su nacimiento y es titular de los derechos patrimoniales y extrapatrimoniales y mixtos que le competen, y puede disfrutar de ellos a través de sí misma o de su representante. Ello sin perjuicio de reconocer al concebido como vida humana, como ser humano, como sujeto de derechos, con sus propios derechos patrimoniales y extrapatrimoniales.

La Constitución de 1993 aprobó en su artículo 2 inciso 1 que "Toda persona tiene derecho: a la vida, a su identidad, a su integridad moral, psíquica y física y a su libre desarrollo y bienestar. El concebido es sujeto de derecho en todo cuanto le favorece". El texto tiene como antecedente directo lo que ya había sido establecido por el Código Civil de 1984, cuando señala en su artículo 1 que "el concebido es sujeto de derecho para todo cuanto le favorece" y que "la atribución de derechos patrimoniales está condicionada a que nazca vivo".
Con ello, la Constitución de 1993, al igual que la legislación civil, acogió la llamada teoría de la subjetividad, siendo una propuesta que en su momento carecía de antecedentes legislativos. Asimismo, ratificó el descarte de la antigua teoría que consideraba al concebido como una parte de la madre (teoría portuio mulieris) y también dejó de lado la clásica y difundida teoría de la ficción; para Fernández Sessarego, la teoría de la ficción era incoherente en tanto para dicha teoría "el concebido es lo que no es -nacido- y cuando es, ya no es -concebido- desde que es persona natural. Es decir, que es y no es al mismo tiempo"3.

Fernández Sessarego tuvo la iniciativa de reconocer al concebido como sujeto de derecho autónomo en el Código Civil de 1984, indicando expresamente que debe ser diferenciado del concepto de persona. El autor, al justificar su propuesta, hace referencia a la necesidad de aprehender sistemáticamente, a nivel normativo, la dimensión sociológico-existencial, que integra el fenómeno jurídico, y en la cual el ser humano se hace presente de cuatro (04) modos: Como concebido, como persona natural, como persona jurídica o como aquellas organizaciones que, comportándose como personas jurídicas, no han cumplido con el requisito de su inscripción en el registro respectivo. ${ }^{4}$
El Estado peruano fue el primero en reconocer la calidad de sujeto de derecho al concebido, estatus jurídico por el cual el "no nacido" deja de ser solo un bien constitucionalmente tutelable para constituirse en un centro de imputación de derechos.

\section{Algunas referencias en la LEGISLACIÓN INTERNACIONAL}

Existe controversia ante el tratamiento legal que debe recibir el concebido; por ejemplo, el Convenio de Derechos Humanos y Europa directamente habla de derecho a la vida, pero no dice "desde la concepción".

Sin embargo una interesante sentencia del Tribunal de Justicia de la Unión Europea, ha resuelto, en octubre de 2011, que no se pueden patentar células madre obtenidas de embriones humanos ni sus materiales biológicos derivados, siendo la referida declaración muy importante porque define al embrión como todo óvulo humano a partir del estadio de la fecundación. ${ }^{5}$

Además, la Declaración Universal sobre Bioética y Derechos Humanos de la UNESCO, si bien reconoce la libertad de investigación científica y tecnológica, destaca que esta se realice en el marco de los principios éticos enunciados en dicha Declaración, tales como: El pleno respeto a la dignidad humana, los derechos humanos y las libertades fundamen-

Para más detalle, véase: Cárdenas Krenz, Ronald. "Dos Interesantes sentencias a propósito de la posibilidad de pantentar embriones y genes”. En: Revista, Persona y Familia. Primer Volumen Nro. 2. Lima, Instituto de Familia. Universidad Femenina del Sagrado Corazón, diciembre 2013. 
tales, también menciona la vital importancia de los intereses y bienestar de la persona sobre el interés exclusivo de la ciencia o la sociedad.

En la legislación comparada, el Distrito Federal de México ha dictado hace no mucho una ley aceptando la maternidad subrogada; con determinados límites. Por su parte, Brasil tiene un decreto por el que acepta en determinadas circunstancias la maternidad subrogada.

En cuanto al requerimiento del consentimiento para la fecundación asistida, en Europa, el artículo $5^{\circ}$ de la Convención Europea de Derechos Humanos y Biomedicina, suscrita en Oviedo el 4 de abril de 1997, requiere el consentimiento informado de la persona interesada para cualquier intervención en su salud, consentimiento que se puede revocar libremente en cualquier momento.

Por su parte, el artículo $6^{\circ}$ de la Declaración Universal de la UNESCO sobre Bioética y Derechos Humanos, de 19 de octubre de 2005, establece que el consentimiento informado debe expresarse y puede ser revocado por la persona interesada en cualquier momento y por cualquier razón sin desventaja o perjuicio para ella.

Entre los Estados miembros de la Unión Europea, el Reino Unido no es el único que ga- rantiza a las dos partes de un tratamiento de reproducción asistida el derecho a revocar el consentimiento al uso o almacenamiento de su material genético. Sin embargo, el momento de revocación de dicho consentimiento no recibe un trato uniforme.

Del informe del Consejo de Europa de 1998, sobre asistencia médica a la procreación y protección del embrión humano (estudio comparativo sobre la situación en treinta y nueve países) se desprende que las leyes danesa, francesa, griega y suiza prevén expresamente el derecho de las partes a revocar el consentimiento en cualquier momento anterior a la implantación. En Holanda, este derecho figura en los textos de aplicación; en Alemania, Bélgica y Finlandia deriva de la práctica clínica, mientras que Islandia, Suecia y Turquía reconocen, en su legislación o en la práctica, el mismo derecho de veto que la ley inglesa. En Austria, Estonia e Italia, el hombre sólo puede revocar su consentimiento hasta la fecundación, momento a partir del cual es la mujer quien decide si continúa con el tratamiento.

\section{Algunas jurisprudencias DE INTERÉS Y OPINIONES DOCTRINARIAS EN EE.UU.}

Si bien los fallos de los tribunales norteamericanos han sido uniformes en cuanto a su resultado, esto es, la pre- valencia de la parte contraria a la implantación de los embriones, los fundamentos de dichas decisiones difieren esencialmente, por lo que cada uno de los casos merece un análisis por separado: Davis v. Davis6 (1992), Kass v. Kass7 (1998), A.Z v. B.Z8 (2001) y J.B v. M.B9 (2001).

Tal como lo ha señalado la doctrina estadounidense, el hecho de que en el caso A.Z y J.B los tribunales respectivos hayan basado su decisión en consideraciones de orden público, alejándose de la presunción de validez y exigibilidad de los acuerdos relativos a embriones criopreservados establecida en Davis y Kass, ello no implica que dicha presunción haya sido completamente desechada por los tribunales de ese país ${ }^{10}$.

Así, no queda claro en los fallos de las Cortes de Massachusetts y Nueva Jersey si todos los acuerdos en esta materia son inexigibles por las partes, o sólo aquellos que podrían obligar a una de ellas a convertirse en padre o madre contra su voluntad. Además, en el caso A.Z, la corte señaló que si bien la procreación forzada es inaceptable, la exigibilidad de un acuerdo que establece la destrucción o la donación de los embriones para fines de investigación es todavía una cuestión abierta ${ }^{11}$.

Sin embargo, ante la aparente preferencia de los tribunales

6 En: Farnós Amorós, Esther (2011), Consentimiento a la Reproducción Asistida. Crisis de pareja y disposición de embriones. Atelier Libros, 2011, p. 842.

Ibídem.

Ibídem.

Ibídem.

10 Ibídem.

11 Ibídem. 
norteamericanos por solucionar estos litigios a través de la preeminencia de la voluntad de las partes, la doctrina de ese país ha señalado una serie de objeciones a la validez y exigibilidad de este tipo de acuerdos.

- Existencia de una carga emotiva y psicológica que generalmente tiene como efecto que el acuerdo suscrito por las partes no sea representativo de su verdadera intención ${ }^{12}$, no estando por tanto las partes en condiciones de entender las implicancias del caso.

- Debe aplicarse el mismo criterio seguido por la jurisprudencia para los acuerdos prenupciales, los cuales sólo se consideran obligatorios en materias pecuniarias que afecten únicamente a los cónyuges, pero no en lo relativo a la custodia, visitas o alimentos debidos a los hijos, ya sea presentes o futu$\operatorname{ros}^{13}$. Así, en los casos de reproducción asistida, los acuerdos también deberían estar sujetos a la revisión y aprobación de los tribunales, sin que deba presumirse su validez y exigibilidad. ${ }^{14}$

- En materia de adopción la situación es similar, ya que en la mayoría de los estados el consentimiento de la madre en orden de dar en adopción a su hijo sólo es válido una vez que el niño ha nacido ${ }^{15}$. El mismo razonamiento puede ser aplicado en el caso de los acuerdos suscritos por una pareja relativos al destino de sus futuros embriones.

- Según la Corte Suprema de EEUU, la mujer puede optar por el aborto en ejercicio de su derecho a la privacidad en materia reproductiva. En el caso Roe, dejó establecido que, bajo la Constitución, el feto no era persona $y$, por tanto, el Estado no podía limitar el derecho de la mujer a disponer de un feto no viable. Por ello, sostuvo que durante los 3 primeros meses de embarazo, la mujer puede terminarlo con razón o sin razón alguna. Del mismo modo, toda mujer a la que se le implantaran embriones podría poner fin al embarazo en el mismo lapso, interpretación que cuestionamos, pues debe priorizarse el derecho a la vida de quien no puede defenderse y por lo tanto es asesinado.

Para otro sector de la doctrina, las decisiones de las cortes de favorecer a la parte contraria a la implantación, discriminan abiertamente a las mujeres que hacen uso de las TERAs en relación a aquellas que pue- den concebir y gestar un hijo naturalmente ${ }^{16}$. Así, una mujer que puede concebir in vivo está plenamente protegida en su derecho fundamental a procrear (o a no procrear) desde el momento de la concepción, mientras que una que debe recurrir a las TERAs pierde tal derecho desde el momento en que el huevo es extraído de su ovario y hasta que el embrión resultante le sea implantado, ya que ante la inexistencia de embarazo físico, los tribunales norteamericanos no consideran que los derechos reproductivos de la mujer puedan ser ejercidos por ésta.

Ahora bien, en las TERAs, si se da a la mujer control sobre los embriones criopreservados hasta la época en que éstos puedan considerarse viables, dicho tiempo podría extenderse indefinidamente, ya que una mujer que se someta a ellas podría dejar pasar meses o años hasta que los embriones le fueran implantados ${ }^{17}$, tornando incierta la situación para el varón, quien no puede ser mantenido indefinidamente en la incertidumbre respecto de si se convertirá en padre o no, con todas las consecuencias psicológicas, emocionales y legales que ello implica.

\section{Análisis del tema}

Como con la concepción se inicia la vida humana, surge entonces el "ser humano gené-

\footnotetext{
Ibídem.

3 Sieck, W. , "In Vitro Fertilization and the Right to Procreate: The Right to No", en: University of Pennsylvania Law Review, Dic. 1998, p. 446.

14 Annas, G. "The Shadowlands: Secrets, Lies and Assisted Reproduction”, en: New England Journal of Medicine. 1998, p. 936.

15 Farnós Amorós, Esther (2011). Op. cit., p. 25.

16 Ibidem, p. 459.

17 Farnós Amorós, Esther (2011). Op. cit., p. 462.
} 
ticamente individualizado"18, por tanto -como dice Fernández Sessarego-, es un sujeto de derecho, digno de protección y tutela. En cuanto ser humano y consiguientemente "sujeto de derecho", posee derechos que protegen sus intereses o exigencias existenciales como son, entre otros, el de su vida e integridad psicosomática.

La capacidad de procrear de la persona no es ilimitada, sino que debe ser realizada dentro de ciertos lineamientos esenciales. Uno de ellos es la defensa y el respeto y consideración que se debe de tener con la vida que ha de generarse. Aquí prima el interés superior del niño que si bien aún no existe, pues no ha sido concebido, tiene todo el derecho de nacer dentro de condiciones naturales, de encontrarse con una familia establecida y de contar con un hábitat adecuado.

La criogenia es un típico acto de manipulación que implica la existencia de aplicación excesiva de técnicas de fecundación extracorpórea, embriones supernumerarios y transferencia embrional.

La ausencia de regulación de embriones crioconservados genera vacíos legales respecto a la disposición de estos en los procesos de divorcio y para el reconocimiento de derechos que tienen los cónyuges sobre ellos.

Estimamos que no debería practicarse la crioconservación de embriones, debido a que la misma vulnera los derechos del concebido, puesto que nadie puede privar al mismo del pleno goce de sus derechos que dimanan y se fundamentan en su propia naturaleza de ser humano.

No existiendo en el Perú un ordenamiento específico que regule las técnicas de reproducción humana asistida, si se examina la legislación encontramos artículos diseminados en diversas leyes, como por ejemplo:

La Ley de Propiedad Industrial (Decreto Legislativo $\mathrm{N}^{\circ}$ $823)$, que señala en su artículo $N^{\circ} 28$, inciso d) que no serán patentables las invenciones sobre las materias que componen el cuerpo humano y sobre la identidad genética del mismo.

El Código de los Niños y Adolescentes (Decreto Ley $\mathrm{N}^{\circ}$ 26102), que establece en su artículo primero que todo niño y adolescente tiene derecho a la vida desde el momento de la concepción. Dicho código garantiza la vida del concebido, protegiéndolo de experimentos o manipulaciones genéticas contrarias a su integridad y desarrollo físico o mental.

La Ley General de Salud (Ley $N^{\circ} 26842$ ) indica en su artículo $\mathrm{N}^{\circ} 7$ que toda persona tiene derecho a recurrir al tratamiento de su infertilidad, así como a procrear mediante el uso de técnicas de reproducción humana asistida, siempre que la condición de madre genética y madre gestacional recaiga sobre la misma persona. Para la aplicación de técnicas de reproducción humana asistida, se requiere del consentimiento previo y por escrito de los padres biológicos.

Está prohibida la fecundación de óvulos humanos con fines distintos a la procreación, así como la clonación de seres humanos.

En este sentido, es de vital importancia contar con una legislación acorde que regule los avances de la genética en beneficio del ser humano, sobre la base de la protección al embrión y a las personas que recurren a las técnicas como beneficiarias, prohibiéndose de manera directa la manipulación de embriones.

Siendo que el concebido, goza del derecho a la vida, que es un derecho extrapatrimonial, irrenunciable y fundamental, ello conlleva a exigir sus otros derechos sin limitación alguna. En consecuencia, nuestra postura es que el congelamiento de embriones debe respetar la calidad humana del embrión, pues en el tratamiento de la fecundación in-vitro se suspende el desarrollo natural psíquico y fisiológico del mismo, no pudiendo ser tratado como objeto para fines de investigación, ni sometido a procesos de selección o congelación, ni mucho menos a su muerte o destrucción.

La práctica de la crioconservación in vitro vulnera el derecho a la vida y, en todo caso, si esta se diera, debería existir el marco legal adecuado para minimizar cualquier

18 Fernandez Sessarego, Carlos (2012). Derecho de las Personas. Editorial Motivensa SRL, Lima, p. 67. 
violación de los derechos del concebido.

La legislación comparada que regula las técnicas de reproducción humana asistida en diversos países europeos, es a veces contradictoria. Pudiendo apreciarse dos tendencias legislativas claramente marcadas: aquella que da prevalencia al desarrollo técnico y la otra que protege a la persona humana.

En nuestro país, desde hace aproximadamente una década, se realizan las técnicas de reproducción humana asistida; a pesar de ello, no existe un cuerpo legal orgánico y sistemático que regule el desarrollo de la genética y su influencia en las relaciones sociales. La falta de un ordenamiento jurídico especializado en nuestro país ocasiona una desprotección no sólo en cuanto a la vida humana sino también en cuanto a la familia y la sociedad en general.

En la actualidad, son los médicos y biólogos de las diversas Clínicas de Fertilidad de nuestro país, quienes en base a criterios éticos personales, aplican sin ningún tipo de regulación legal las técnicas de reproducción humana asistida.

El concebido es un ser humano, sujeto de derechos y se debe proteger sus intereses y exigencias existenciales como son: La vida y la integridad, motivo por el cual coincido con Rubio Correa quien señala que "el Concebido es vida humana que aún no ha nacido, pero que tiene existencia para el Derecho, la vida humana comienza con la concepción." 19

Además, como señala el profesor y genetista español Nicolas Jovue: "Lo que hay antes y lo que hay después es el mismo ente, no hay uno anterior ni uno posterior. Si esto es así desde el punto de vista biológico, pues lo debe ser también desde el antropológico y desde cualquier otra consideración". Agrega, en sustentada crítica a quienes sostienen que la vida empieza con la anidación, que "La implantación es un elemento más, pero no es el elemento determinante entre lo que debe considerarse persona o no persona". ${ }^{20}$

Entonces, tenemos que la vida humana empieza con la concepción y que el concebido, aunque incapaz de entender y de querer y hasta un cierto periodo de expresar sus sentimientos, es un fin en sí mismo y no puede ser reducido a la calidad de medio o instrumento para lograr otros fines.

El concebido es el ser humano antes de nacer que pese a que depende de la madre para su subsistencia, está genéticamente individualizado frente al ordenamiento jurídico y, como tal, se convierte en un centro de imputación de deberes y derechos que lo favorecen. Es por eso que se define que es un sujeto de "derecho favorecido".

\section{Algunas Reflexiones finales}

Consideramos que, en primer lugar, a pesar de todos los beneficios que puede traer la reproducción asistida a la reproducción humana, permitiendo que se pueda concebir con ayuda de la ciencia, debe ponerse de manifiesto la existencia de otras opciones alternativas y, si fracasan, se tiene que aceptar la esterilidad de forma más que definitiva.

Las parejas que no pueden reproducirse naturalmente pueden recurrir a la reproducción asistida, conforme a los establece la Ley General de Salud, pero el proceso de crioconservación de embriones debería prohibirse porque atenta contra la vida humana. Empero, siendo que en la práctica se da, estimamos que, en todo caso, debería regularse la misma.

En la jurisprudencia extranjera, los tribunales superiores estadounidenses, respecto al destino de los embriones criopreservados, no han sido uniformes en cuanto a favorecer a la parte contraria a la implantación, los fundamentos jurídicos de dichas resoluciones son diversos e incluso opuestos. Así, en Davis y Kass, los tribunales respectivos establecieron como principio la validez y exigibilidad de los acuerdos de las partes en esta materia. Sin embargo, en dos casos posteriores, $A . Z$ y J.B, la decisión estuvo basada en consideraciones de orden público, que de acuerdo al razonamiento de los tribunales no permiten imponer acuerdos que tienen como efecto ligar a un individuo con una futura descendencia. Nuestra postura ante

19 Rubio Correa, Marcial (1999). Estudio de la Constitución Política de 1993. Tomo I. Lima, Fondo Editorial PUCP, p. 26.

20 Entrevista a Nicolás Jouve. En: Diario El Comercio. Lima, edición del 15.06.2013, p. A-26 
esto es que definitivamente es imprescindible regular el uso del material genético, siendo que en esta materia se presentan casos similares a estos en nuestro país que no tienen asidero legal y que son tratados de manera incipiente, causando una desprotección tanto para el crioconservado como para los sujetos involucrados en el conflicto de intereses.

Tampoco la doctrina tiene una postura única respecto del tema. Si bien parece haber unanimidad en cuanto al rechazo de resolver estas disputas por medio de los acuerdos previos de las partes, para algunos autores la implantación requiere siempre del consentimiento contemporáneo de los progenitores, por lo que, en caso de desavenencia, los embriones deberían ser destruidos o donados para fines de investigación. En este punto, planteamos que no debería hacerse uso indiscriminado de los embriones, por ser vidas humanas que merecen un tratamiento constitucional $y$ deberían establecerse límites para su utilización.

Por su parte, otro sector de la doctrina estima que debe igualarse la situación de la mujer que se somete a estos procedimientos con la de una mujer capaz de concebir en vivo, por lo que debe darse a la madre pleno control sobre los embriones criopreservados durante un término análogo al establecido por la jurisprudencia relativa al aborto. De esta manera, el futuro de los embriones que se encuentran en estado de crioconservación en las clínicas es incierto, ya que en definitiva los progeni- tores no pueden estar seguros de si los acuerdos suscritos por ellos serán respetados y deberían respetarse, protegiendo al crioconservado.

Cuando nos referimos a aquel ser humano que se halla en un banco de preembriones y por ende, no se encuentra en el útero de la mujer, hablamos de la necesidad de buscar una fase de gestación o desarrollo para el crioconservado, y frente a un proceso de divorcio de sus progenitores, este debe ser implantado en la madre genética, y de existir un acuerdo entre ambos progenitores, podría donarse a una pareja infértil. Pero bajo ningún motivo puede eliminarse dicho embrión, por lo que debe respetarse los derechos del mismo, permitiéndole así su desarrollo.

Tal como se aplica en otros países, se debería establecer el tratamiento del nasciturus y el destino que se le dará, en el caso de fallecimiento de la madre, ya que el nasciturus ya no podrá ser gestado por ella $y$, al no poder transferirse al marido, con el transcurso de un tiempo pasará a disposición del Banco autorizado, en cuyo caso se debe considerar a todos los efectos con las mismas consecuencias que si procediera de donación, es decir, que en ningún caso se determinará la filiación y será madre legal no la madre genética, sino la gestante.

No debería restringirse la protección y salvaguarda que los embriones en crioconservación merecen, pues estamos frente a una vida humana y debe respetarse los derechos que posee; debiendo constituirse todos los mecanismos para que sea fertilizado en un útero materno y cumpla la finalidad para la cual fue fecundado.

\section{REFERENCIAS BIBLIOGRÁFICAS}

Annas, G., "The Shadowlands: Secrets, Lies and Assisted Reproduction", en: New England Journal of Medicine. 1998.

Cárdenas Krenz, Ronald. “Dos Interesantes sentencias a propósito de la posibilidad de pantentar embriones y genes". En: Revista del Instituto de Familia Derecho, Persona y Familia. Primer Volumen Nro. 2. Lima, Universidad Femenina del Sagrado Corazón, diciembre 2013.

Farnós Amorós, Esther. Consentimiento a la Reproducción Asistida. Crisis de pareja y disposición de embriones. Atelier Libros, 2011.

Fernández Sessarego, Carlos. Nuevas Tendencias en el Derecho de las Personas. Lima, Universidad de Lima, 1997.

Fernández Sessarego, Carlos. Derecho de las Personas. Editorial Motivensa SRL, Lima, 2012.

Jouve de la Barreda, Nicolas; El Manantial de la Vida. Genes y Bioética. Ediciones Encuentro. Madrid, 2013.

León Barandiarán, José. Curso Elemental de Derecho Civil Peruano. Segunda Edición. Lima, Imprenta de la Universidad Nacional Mayor de San Marcos, 2001. 
Sieck, W., "In Vitro Fertiliza- Rubio, Marcial. Estudio de la tion and the Right to Procreate: The Right to No", en: University of Pennsylvania Law Review, diciemConstitución Política de 1993. Tomo I. Lima, Fondo Editorial PUCP, 1999. bre 1998. 